\title{
CORRELAÇÃO DE ANÁLISE FISICO-QUÍMICA E ESPECTRORRADIOÉTRICA DE AMOSTRAS DE SOLO DA BACIA DO RIO SUBAÉ.
}

\author{
$\underline{\text { Ayala de Souza Reis Carneiro }}{ }^{1}$ e Taíse Bomfim de Jesus ${ }^{2}$ \\ 1. Bolsista PROBIC/UEFS, Graduando em Engenharia Agronômica, Universidade Estadual de Feira de \\ Santana, e-mail: ayala.reis@ @otmail.com \\ 2. Orientador, Departamento de Ciências Exatas, Universidade Estadual de Feira de Santana, e-mail: \\ taisebj@hotmail.com
}

PALAVRAS-CHAVE: comportamento espectral; matéria orgânica; óxidos de ferro.

\section{INTRODUÇÃO}

Estudos recentes demonstram que o sensoriamento remoto vem se constituindo como meio imprescindível no estudo de solos, permitindo a aquisição sistemática de dados hiperespectrais uteis para o conhecimento dos atributos deste sistema. $\mathrm{O}$ comportamento espectral do solo é condicionado por todos os elementos que o constitui, em especial o teor de matéria orgânica e óxidos de ferro (DEMATTÊ \&GARCIA, 1999).

A viabilidade da quantificação de atributos do solo por meio de sua curva espectral baseia-se na intensidade da curva, assim como nas absorções de energia eletromagnética em pontos específicos ou em intervalos da curva, uma vez que diferentes quantidades de certos atributos presentes no solo podem aumentar ou diminuir a reflectância espectral em diferentes comprimentos de onda do espectro eletromagnético (NANNI, 2000). As curvas espectrais apresentam feições típicas ou bandas de absorção, devido a interação dos átomos e moléculas dos diferentes constituintes do solo com a radiação eletromagnética em um dado comprimento de onda específico

O presente trabalho objetivou correlacionar resultados analíticos com dados radiométricos de amostras de solo do Centro de Agroecologia Rio Seco (CEARIS UEFS), Amélia Rodrigues, Bahia.

\section{MATERIAL E MÉTODOS OU METODOLOGIA (ou equivalente)}

As áreas de estudo foram compostas de duas áreas de solo com cobertura de pastagem cultivada, localizadas no Centro de Agroecologia Rio Seco (CEARIS UEFS), estando localizadas no município de Amélia Rodrigues, Bahia, na bacia do Rio Subaé. O CEARIS conta com uma área de aproximadamente 25 hectares, sendo que as áreas de estudo: área $01 \mathrm{com} 858,53 \mathrm{~m}^{2}$, e área 02 com 1.023,1 m².

Procedeu-se amostragem nos meses de dezembro/2016 e fevereiro/2017 nas áreas de estudo, seguindo a metodologia recomendada por Silva et al., (2009) para áreas de pastagem: com uso de um trado holandês, coletando amostras de 0 a $20 \mathrm{~cm}$ de profundidade no solo, percorrendo cada área para melhor caracterizar o ambiente de estudo, com um total de 9 amostras simples por área, para formar uma amostra composta (de cada área). As amostras foram acondicionadas e armazenadas em sacos plásticos e transferidas para o laboratório.

As medidas radiométricas foram realizadas no Laboratório de Espectrorradiometria do Programa de Pós Graduação em Modelagem em Ciências da Terra e do Ambiente (PPGM), localizado na Universidade Estadual de Feira de Santana (UEFS). 
O sensor utilizado para obtenção das curvas espectrais foi o espectrorradiômetro FieldSpec 3 (ASD Inc. - A PANalytical Company®), com faixa espectral de captação de sinal de 350 à $2.500 \mathrm{~nm}$ com 2.151 bandas do espectro eletromagnético, resolução de $3 \mathrm{~nm}$ até $700 \mathrm{~nm}$ e de $8 \mathrm{~nm}$ até $1.400 / 2.100 \mathrm{~nm}$.

A reflectância é calculada pelo algoritmo representado na equação 1 .

$$
\rho=100 \times L / E
$$

Em que $L$ é a intensidade da energia que deixa a amostra (radiância das amostras de solo) e $E$ é a energia incidente, irradiância da fonte (Luz). Ambos os valores dados em W.cm- ${ }^{2}$, sendo a reflectância calculada em W.cm- ${ }^{2} \cdot \lambda-^{-1}$, contudo, é dada em valor percentual.

A determinação analítica de MO seguiu a NBR 13.600 que é a determinação do teor de matéria orgânica por queima em alta temperatura. A determinação de ferro nas amostras de solo foi realizada utilizando a espectrometria de absorção atômica.

\section{RESULTADOS E/OU DISCUSSÃO (ou Análise e discussão dos resultados)}

A figura 3 refere-se as leituras espectral das duas áreas avaliadas nos referidos meses de amostragem (em azul - área 01, e em vermelho - área 02). As assinaturas apresentaram diferença no tamanho do albedo. Característicos da absorção nas regiões referentes aos atributos do solo estudado; matéria orgânica e óxidos de ferro.

A.
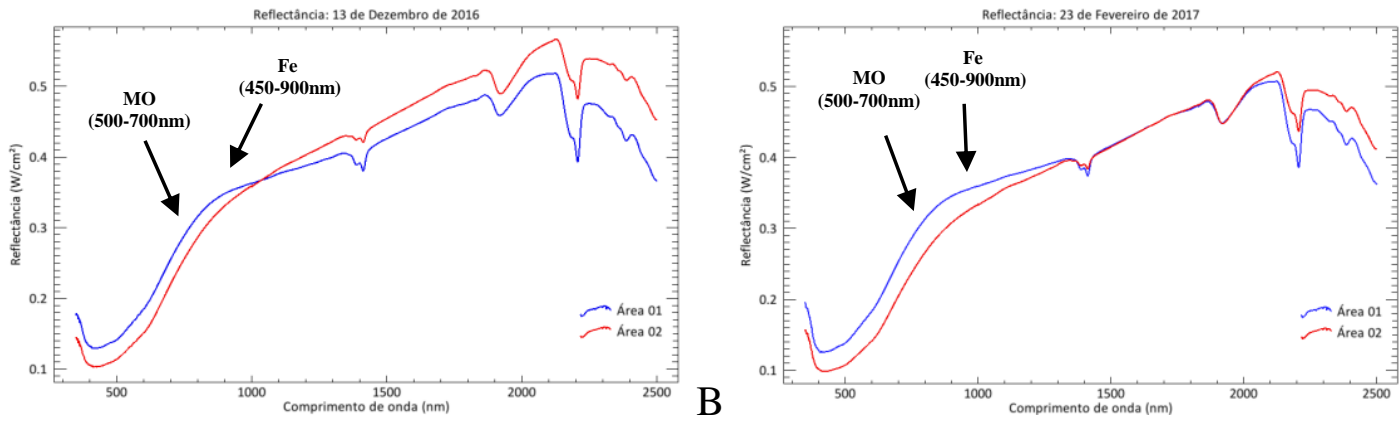

Figura 1: Espectros de reflectância de amostras de solos do Centro de Agroecologia Rio Seco (CEARIS - UEFS), - Amélia Rodrigues- Bahia: A - dezembro de 2016 e B fevereiro de 2017.

Na tabela 1, encontram-se os resultados analíticos referentes aos teores de matéria orgânica (MO) obtidos em cada área de estudo em ambos os meses de amostragem.

Tabela 1: Teores de matéria orgânica encontrados nos solos m estudo.

\begin{tabular}{|c|c|c|}
\hline \multicolumn{3}{|c|}{ Teor de Matéria } \\
\hline Lrgânica (\%) \\
\hline Local & Dez./2016 & Ferv./2017 \\
\hline Área 01 & 2.84 & 7.76 \\
\hline Área 02 & 3.83 & 4.87 \\
\hline
\end{tabular}

De acordo com Dalmolin (2005) além de feições específicas de absorção, a reflectância é caracterizada pela forma e pelo albedo da curva espectral. Muitos estudos descrevem o papel da MO no comportamento espectral do solo, Krishman et. al. (1980) apresenta estudos que estabelecem intervalos espectrais que são utilizados em algoritmos para predizer seu teor no solo, estabelecendo características de absorção em bandas na região do visível, compreendendo o intervalo de comprimento de onda de 500 a $700 \mathrm{~nm}$. 
A figura 1 apresenta maior albedo na área $01 \mathrm{em}$ ambos os meses (Figura $1 \mathrm{~A} \mathrm{e}$ B), apresentando maiores valores de reflectância, para o comprimento de onda característico da MO. Em estudos para o teor de matéria orgânica do solo, Balena (2011); Dalmolin et al. (2005); Bellinaso (2009), relatam que neste intervalo de comprimento de onda, quanto menor a reflectância maior é o teor de matéria orgânica, ou seja, ocorre a diminuição da intensidade da curva espectral, corroborando com os valores analíticos obtidos no mês de dezembro de 2016.

Metodologia utilizada para determinação de MO não correspondeu significativamente aos resultados encontrados, onde ocorreu divergência nos resultados obtidos a partir da análise física e da leitura do espectro. Outros fatores podem ter influenciado nessa discordância, de acordo com Dalmolin et al (2005), além do seu teor os componentes da MO influenciam no comportamento espectral. Constituintes orgânicos, como ácidos húmicos e fúlvicos, são relevantes por interferir diferentemente na reflectância do solo, onde possuem diferentes coeficientes de radiância. $\mathrm{O}$ grau de decomposição da MO, tais como; material sáprico (altamente decomposto), hêmico (moderadamente decomposto) e fíbrico (ligeiramente decomposto), apresentam valores de absorção diferente influenciando diretamente nos valores de reflectância obtidos. BEN-DOR et al. (1997) verificaram que as oscilações no comportamento espectral na região do visível e infravermelho próximo estavam correlacionadas a relação Carbono/Nitrogênio.

Na tabela 2, encontram-se os resultados analíticos obtidos das concentrações de ferro em cada área de estudo e em ambos os meses de amostragem.

Tabela 2: Concentrações de ferro encontradas nas áreas de coleta.

\begin{tabular}{|l|c|c|}
\hline \multicolumn{3}{|c|}{ Concentração de Ferro (mg.Kg- ${ }^{\mathbf{1}}$ ) } \\
\hline Local & Dez./2016 & Ferv./2017 \\
\hline Área 01 & 21,098 & 20,703 \\
\hline Área 02 & 10,259 & 9,568 \\
\hline
\end{tabular}

As curvas espectrais obtidas apresentam maior albedo para a área 01, em ambos os meses de amostragem (Figura 1 A e B). No intervalo de comprimento de onda que vai de 450nm à $900 \mathrm{~nm}$, Alvarenga et al.(2003); Balena (2011); Bellinaso (2009); Stoner et al.(1980), relatam que o albedo diminui à medida que a quantidade de óxidos de ferro aumenta no solo. Neste sentido, os resultados analíticos obtidos (tabela 2) e as leituras do espectro (figura 1) divergem entre si, pois em ambos os meses a área 01 apresentou valores de reflectância maior que a área 02 , ou seja, não correspondem com as concentração de ferro obtidas.

As concentrações de ferro obtidas não foram satisfatórias. A utilização de ácidos fracos (ácido clorídrico e nítrico) na digestão da amostra pode ter interferido nos resultados, pois esses ácidos não possibilitam a digestão completa do solo, permanecendo a presença da sílica. Outra possível hipótese da não concordância das análises é o teor de MO no solo, segundo Dalmolin et al (2005) a MO pode desempenhar o efeito de máscara, diminuindo feições de absorção de outros constituintes, teores de MO superior a $17 \%$ presente no solo obstruíram o efeito dos óxidos de ferro na reflectância e na cor do solo. Entretanto os teores de MO obtidos na análise física não relatam essa interferência.

Além do teor de MO, os minerais de matiz avermelhado (hematita) e matiz amarelo (goethita) afetam o comportamento espectral do solo, influenciando o comportamento da curva principalmente na região do visível, infravermelho próximo e infravermelho médio, possibilitando a diminuição do albedo de acordo com o aumento do seu teor no solo (DALMOLIN et al, 2005). Demattê e Garcia (1999) relata que a 
cristalinidade dos minerais de ferro presente no solo influenciam na intensidade da reflectância espectral.

\section{CONSIDERAÇÕES FINAIS (ou Conclusão).}

A espectroscopia é uma técnica que vem ganhando espaço no estudo de solos, trabalhos como este demonstram a capacidade de predizer características peculiares dos diferentes solos, ao confrontar com dados químicos. Podendo-se obter informações de maneira rápida e não destrutiva da constituição dos solos em nível de laboratório.

No presente trabalho observou-se a relação entre o comportamento das curvas espectrais e as concentrações dos diferentes constituintes do solo, estudados. Ao confrontar os resultados encontrados ocorreu uma discordância, que pode estar relacionada a metodologia de análise físico-química ou a interferência dos diferentes constituintes do solo no comportamento espectral do mesmo.

\section{REFERÊNCIAS}

ALVARENGA, B. S; D’ARGO, E.; ADAMI, M.; FORMAGGIO, A. R.; - Manual de Referência. In: Simpósio Brasileiro de Sensoriamento Remoto, 11, Belo Horizonte, 2003. Anais. São José dos Campos: INPE, 1993. p. 2-12.

ASSOCIAÇÃO BRASILEIRA DE NORMAS TÉCNICAS. NBR 13600: SoloDeterminação do teor de matéria orgânica por queima a $440^{\circ} \mathrm{C}$. Rio de Janeiro: Globo, 1996.

BALENA, S. P. Correlação de análises fisico-químicas e espectroscópicas de laboratório com dados obtidos em campo por espectrorradiômetro. 2011. $105 \mathrm{f}$. Tese (Doutorado) - Curso de Química, Ciências Exatas, Universidade Federal do Paraná, Curitiba, 2011.

BELLINASO, H. Biblioteca espectral de solos e sua aplicação na quantificação de atributos e classificação. 2009. 265 f. Dissertação (Mestrado) - Curso de Agronomia, Universidade de São Paulo Escola Superior de Agricultura " Luiz de Queiroz", Piracicaba, 2009.

BEM-DOR, E. et al. The reflectance spectra of organic matter in the visible nearinfrared and short wave infrared region (400-2500) during a controlled decomposition process. Remote Sensing of Environment, New York, v.61, p. 1-15, 1997.

DALMOLIN, R. S. D. et al. Relação entre os constituintes do solo e seu comportamento espectral. Ciência Rural, Santa Maria, v. 35, n. 2, p.481-489, mar./abr. 2005.

DEMATTÊ,J.A.M..;GARCIA, G.J. Alteration of soil properties though a weathering sequence as evaluated by spectral refletance. Soil Science Society of America Journal, Madison, v.63, p.327-342, 1999.

KRISHNAN,P. et al. Reflectance technique for predicting soil organic matter. Soil Science Society of America Journal, Madison, v.44, p.1282-1285,1980.

NANNI, M. R. Dados radiométricos obtidos em laboratório e no nível orbital na caracterização e mapeamento dos solos. 2000. 366p. Tese (Doutorado em Agronomia) Escola Superior de Agricultura "Luiz de Queiroz"-USP, Piracicaba, 2000.

SILVA, Fábio Cesar da et al (Org.). Manual de análises químicas de solos, plantas e fertilizantes. 2. ed. Brasília: Embrapa, 2009. 627 p.

STONER, E.R et al. Atlas of soil reflectance properties. West Lafayette : Purdue University, 1980. 75

STONER,E.R. Physicochemical, site and bi-directional reflectance fator characteristics of uniformly moist soils. 1979. 132f.Theis ( $\mathrm{PhD}$ in soil Science) Purdue university. 